\title{
Case Report: Successful use of fondaparinux in a case of heparin intolerance during pregnancy [version 1; peer review:
}

\section{2 not approved]}

\author{
Mohammed AISheef (iD1, Noura Shafi', Bakhitah Aleid1, \\ Abdul Rehman Zia Zaidi(D1,2, Ohoud AlArfaj3 \\ ${ }^{1}$ Department of Medicine, King Fahad Medical City, Riyadh, 11525, Saudi Arabia \\ ${ }^{2}$ College of Medicine, Alfaisal University, Riyadh, 11525, Saudi Arabia \\ ${ }^{3}$ Department of Clinical Pharmacy, King Fahad Medical City, Riyadh, 11525, Saudi Arabia
}

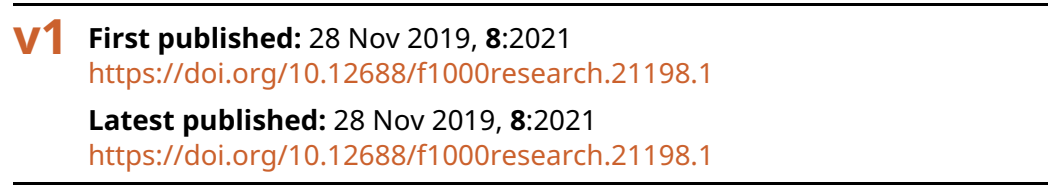

\section{Abstract}

Heparin is the anticoagulant of choice during pregnancy. However, in cases of intolerance or adverse effects, another anti-coagulant agent should be administered. Here, we describe a case of hypersensitivity skin reaction seen in a 37-year-old pregnant patient at 11 weeks of gestation who used low-molecular-weight heparin (LMWH).

Fondaparinux was used as an alternative during her pregnancy with a successful outcome.

\section{Keywords}

Fondaparinux, Heparin Intolerance, Pregnancy, LMWH, Hypersensitivity, Anticoagulant

\section{Open Peer Review}

Approval Status $\mathrm{X} X$

1

2

version 1

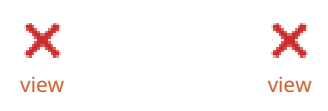

1. Saskia Middeldorp, Amsterdam UMC, University of Amsterdam, Amsterdam, The Netherlands

Hanke Wiegers, Amsterdam UMC, University of Amsterdam, Amsterdam, The Netherlands

2. Maha Othman (iD, Queen's University,

Ontario, Canada

Any reports and responses or comments on the article can be found at the end of the article. 
Corresponding author: Mohammed AISheef (malsheef@kfmc.med.sa)

Author roles: AISheef M: Conceptualization, Data Curation, Project Administration, Supervision, Validation, Visualization, Writing Original Draft Preparation, Writing - Review \& Editing; Shafi N: Conceptualization, Investigation, Methodology, Project Administration, Writing - Original Draft Preparation; Aleid B: Conceptualization, Investigation, Methodology, Project Administration, Writing - Original Draft Preparation; Zaidi ARZ: Formal Analysis, Visualization, Writing - Original Draft Preparation, Writing - Review \& Editing; AIArfaj O: Conceptualization, Investigation, Methodology, Project Administration, Supervision, Writing - Original Draft Preparation

Competing interests: No competing interests were disclosed.

Grant information: The author(s) declared that no grants were involved in supporting this work.

Copyright: $\odot 2019$ AlSheef $\mathrm{M}$ et al. This is an open access article distributed under the terms of the Creative Commons Attribution License, which permits unrestricted use, distribution, and reproduction in any medium, provided the original work is properly cited.

How to cite this article: AlSheef M, Shafi N, Aleid B et al. Case Report: Successful use of fondaparinux in a case of heparin intolerance during pregnancy [version 1; peer review: 2 not approved] F1000Research 2019, 8:2021

https://doi.org/10.12688/f1000research.21198.1

First published: 28 Nov 2019, 8:2021 https://doi.org/10.12688/f1000research.21198.1 


\section{Introduction}

Low-molecular-weight heparin (LMWH), such as enoxaparin, is the preferred anticoagulant for pregnant women due to its effectiveness, safety, and availability. However, if the pregnant patient experiences an allergy, side effect or intolerance, she should be switched to alternative anticoagulation medication. Unfortunately, in such circumstances, the other anti-coagulation options are limited due to teratogenicity, lack of literature support, or cross-reactivity with LMWH.

Fondaparinux, which is a synthetic polysaccharide inhibitor of activated factor $\mathrm{X}$ ( $\mathrm{FXa})$, has been reported to be a successful alternative anticoagulant in pregnant patients who develop heparin intolerance, such as hypersensitivity skin reaction, which is frequently seen in pregnant patients ${ }^{1}$. Although it crosses the placental barrier and results in low measurable anti-factor Xa activity in umbilical-cord blood $^{2}$, it is considered relatively safe since there are no significant reported unfavorable side effects for the mother or child during pregnancy or the postpartum period.

\section{Case report}

A 37-year-old Saudi female homemaker (G6P4+1) with a history of hypothyroidism on thyroxin and a history of miscarriage and intrauterine fetal death (IUFD) presented to our thrombosis clinic. She explained to us that this is an important pregnancy for her and that she wished to deliver a healthy baby. Her gynecological history comprised of: preeclampsia during her first pregnancy, resulting in premature labor; fetal distress during her second pregnancy; a third pregnancy resulting in premature labor at 30 weeks; a fourth pregnancy resulting in IUFD at 25 weeks; fetal distress in the $31^{\text {st }}$ week of her fifth pregnancy in 2012; and a sixth pregnancy resulting in IUFD in 2015. Therefore, she was referred to our tertiary care hospital and to our clinic to prevent morbidity and mortality in the current pregnancy. She presented to our clinic in 2016, 11 weeks pregnant, and on physical examination, cardiac and respiratory exams were normal. Abdominal examination showed a gravid uterus. Thrombophilia work up including protein $\mathrm{C}$, protein $\mathrm{S}$, antithrombin III, factor $\mathrm{V}$ Leiden mutation, prothrombin gene mutation G20210A, and antiphospholipid antibodies were within normal limits (Table 1).

The patient was started on aspirin $81 \mathrm{mg}$ once daily, and low-molecular-weight-heparin (LMWH) 4000 units via subcutaneous injection once daily. We explained to the patient the rationale for using heparin was to prevent placental microvascular thrombosis and therefore, prevent placental mediated complications such as preeclampsia and IUFD. This is an internationally recommended evidence-based practice.

Five days later, she developed a severe rash, as depicted in Figures 1A-1D. Hence, LMWH was discontinued, and she was asked to resume taking aspirin $81 \mathrm{mg}$ once daily. She was

Table 1. Laboratory values at the initial presentation and at follow-up visits.

\begin{tabular}{|c|c|c|c|c|}
\hline Test & $\begin{array}{l}\text { Value at initial } \\
\text { presentation }\end{array}$ & $\begin{array}{l}\text { Value at follow- } \\
\text { up visits }\end{array}$ & $\begin{array}{l}\text { Value at six weeks } \\
\text { postpartum }\end{array}$ & Reference range \\
\hline White blood cells & $7.47 \times 10^{9} / \mathrm{L}$ & $7.28 \times 10^{9} / \mathrm{L}$ & $7.87 \times 10^{9} / \mathrm{L}$ & $4-11 \times 10^{9} / \mathrm{L}$ \\
\hline Hemoglobin & $13.0 \mathrm{~g} / \mathrm{dL}$ & $14 \mathrm{~g} / \mathrm{dL}$ & $12.6 \mathrm{~g} / \mathrm{dL}$ & $12-16 \mathrm{~g} / \mathrm{dL}$ \\
\hline Platelets & $300 \times 10 \% / L$ & $350 \times 10^{9} / \mathrm{L}$ & $332 \times 10^{9} / \mathrm{L}$ & $155-435 \times 10^{9} / \mathrm{L}$ \\
\hline Creatinine & $41 \mu \mathrm{mol} / \mathrm{L}$ & $54 \mu \mathrm{mol} / \mathrm{L}$ & $58 \mu \mathrm{mol} / \mathrm{L}$ & $44-80 \mu \mathrm{mol} / \mathrm{L}$ \\
\hline Aspartate aminotransferase & $18 \mathrm{U} / \mathrm{L}$ & $19 \mathrm{U} / \mathrm{L}$ & $21 \mathrm{U} / \mathrm{L}$ & $0-32 \mathrm{U} / \mathrm{L}$ \\
\hline Alanine amino transferase & $8 \mathrm{U} / \mathrm{L}$ & $11 \mathrm{U} / \mathrm{L}$ & $12 \mathrm{U} / \mathrm{L}$ & $0-31 \mathrm{U} / \mathrm{L}$ \\
\hline Alkaline phosphatase & $124 \mathrm{U} / \mathrm{L}$ & $131 \mathrm{U} / \mathrm{L}$ & $121 \mathrm{U} / \mathrm{L}$ & $50-136 \mathrm{U} / \mathrm{L}$ \\
\hline Activated partial thromboblastin time & $26.4 \mathrm{sec}$ & $28 \mathrm{sec}$ & $28 \mathrm{sec}$ & $26-40 \mathrm{sec}$. \\
\hline International normalized ratio & 0.9 & 1.1 & 1.0 & $0.9-1.2$ \\
\hline \multicolumn{5}{|l|}{ Thrombophilia Work-up } \\
\hline Anticardiolipin screen IgG & 10.7 & $\mathrm{n} / \mathrm{a}$ & $n / a$ & $<12.5$ \\
\hline Anticardiolipin screen IgM & 3.48 & $\mathrm{n} / \mathrm{a}$ & $\mathrm{n} / \mathrm{a}$ & $0-14.9$ \\
\hline Anticardiolipin screen IgA & $<8.0$ & $\mathrm{n} / \mathrm{a}$ & $n / a$ & $<12$ \\
\hline B2 - Glycoprotein I IgG & $2.3 \mathrm{U} / \mathrm{mL}$ & $\mathrm{n} / \mathrm{a}$ & $\mathrm{n} / \mathrm{a}$ & 0-20 U/mL \\
\hline B2 - Glycoprotein I IgM & $5.6 \mathrm{U} / \mathrm{mL}$ & $\mathrm{n} / \mathrm{a}$ & $\mathrm{n} / \mathrm{a}$ & 0-20 U/mL \\
\hline B2-Glycoprotein I IgA & $19.1 \mathrm{U} / \mathrm{mL}$ & $\mathrm{n} / \mathrm{a}$ & $\mathrm{n} / \mathrm{a}$ & $0-20 \mathrm{U} / \mathrm{mL}$ \\
\hline Protein S & $78.4 \%$ & $\mathrm{n} / \mathrm{a}$ & $n / a$ & $50-123 \%$ \\
\hline Protein C & $94.2 \%$ & $\mathrm{n} / \mathrm{a}$ & $\mathrm{n} / \mathrm{a}$ & $70-140 \%$ \\
\hline Antithrombin III & $101.2 \%$ & $\mathrm{n} / \mathrm{a}$ & $\mathrm{n} / \mathrm{a}$ & $70-125 \%$ \\
\hline Lupus anticoagulation - La1 & $35.4 \mathrm{sec}$ & $\mathrm{n} / \mathrm{a}$ & $\mathrm{n} / \mathrm{a}$ & $31-44 \mathrm{sec}$ \\
\hline Factor V Leiden (APCR) & 1.2 & $n / a$ & $\mathrm{n} / \mathrm{a}$ & $0.69-2.0$ \\
\hline Prothrombin gene mutation G20210A & Negative & $n / a$ & $\mathrm{n} / \mathrm{a}$ & Negative \\
\hline
\end{tabular}



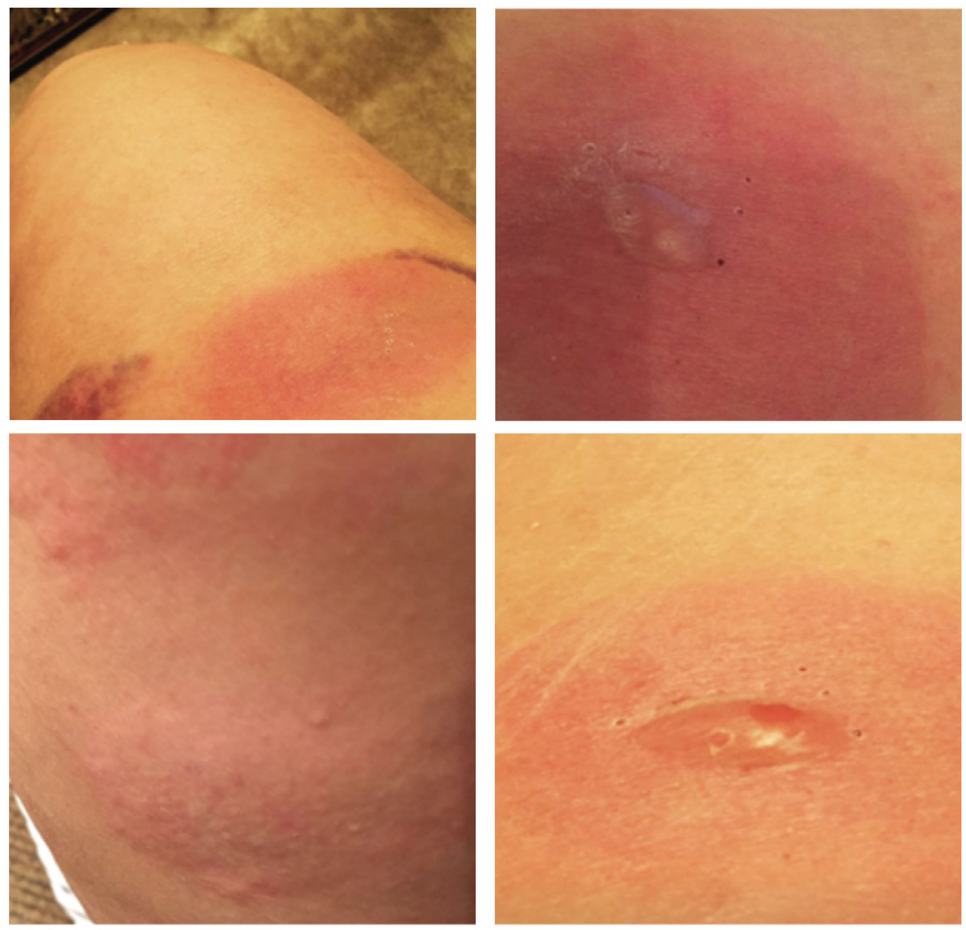

Figure 1. A-D) The composite figure illustrates clinical findings, showing the patient's rash, when she was administered low-molecular weight heparin.

found to be allergic to LMWH (such as enoxaparin and tinzaparin), resulting in symptoms such as swelling, itching, and erythema, which slowly resolved one week after discontinuation of heparin. One month later, on her scheduled follow-up appointment with us, she no longer had any skin rash or any other hypersensitivity reaction symptoms. We suggested fondaparinux $2.5 \mathrm{mg}$ delivered subcutaneously once daily. We explained to the patient that fondaparinux was an alternative anticoagulant for patients intolerant to heparin, with no reported hypersensitivity reactions or adverse effects on the fetus. She agreed, and hence we discontinued aspirin and started her on fondaparinux. We monitored her health through monthly follow-up clinic visits with regular laboratory tests and ultrasounds in the maternal fetal medicine and thrombosis clinics (Table 1). The ultrasounds had no significant findings, with a single viable fetus and normal growth. She was well with no allergic symptoms or discomfort, and kept taking fondaparinux for five months until her planned induction of labor at 38 weeks gestation with cessation of fondaparinux for 24 hours. She delivered a normal healthy baby and we followed up regularly with the patient for six weeks postpartum (Table 1).

\section{Discussion}

Heparin has always been the anticoagulant of choice to prevent and treat a thrombotic event during pregnancy ${ }^{1}$. However, its use is limited when adverse reactions such as skin rash (type I hypersensitivity reaction) or heparin-induced thrombocytopenia occurs. Hence, in the setting of heparin intolerance with a high risk of thrombosis, alternative choices for anticoagulation becomes limited.

Current evidence shows that fondaparinux is a safe and effective alternative option in the circumstances, such as seen in our case ${ }^{2-4}$. For instance, a retrospective study comparing the efficacy of fondaparinux to enoxaparin in terms of pregnancy success rate, gestational age, birth weight, and major bleeding complications concluded that both anticoagulants have comparable results ${ }^{5}$. In addition, a prospective study evaluating the effect of a prophylactic dose of fondaparinux in pregnant women with a history of venous thromboembolism reported $100 \%$ uneventful pregnancies without thromboembolic complications ${ }^{6}$. However, there is limited experience in the use of fondaparinux in pregnancy, but it has been used in patients with heparin intolerance with no reported adverse effects to the fetus or the mother?

In concordance with the literature, our patient had an uneventful pregnancy without developing an adverse reaction to fondaparinux. With regards to the long-term safety of fondaparinux, several studies in the literature reported no significant difference in safety profile compared to enoxaparin over a period of therapy ranging between a few weeks to eight months.

On the other hand, umbilical blood sampling showed a detectable level of anti-factor Xa, indicating the passage of fondaparinux to fetal circulation. However, the accumulative 
level is measured and found to be subtherapeutic, and no study reported any complications during pregnancy or post-partum ${ }^{8}$.

\section{Conclusion}

In conclusion, our case demonstrates that fondaparinux is a safe and effective anticoagulant option in the presence of heparin intolerance.

\section{Data availability}

All data underlying the results are available as part of the article and no additional source data are required.

\section{Consent}

Written informed consent for publication of their clinical details and clinical images was obtained from the patient.
1. Mazzolai $L$, Hohlfeld $P$, Spertini $F$, et al:: Fondaparinux is a safe alternative in case of heparin intolerance during pregnancy. Blood. 2006; 108(5): 1569-1570. PubMed Abstract | Publisher Full Text

2. Ciurzyński M, Jankowski K, Pietrzak B, et al.: Use of fondaparinux in a pregnant woman with pulmonary embolism and heparin-induced thrombocytopenia. Med Sci Monit. 2011; 17(5): CS56-CS59. PubMed Abstract | Publisher Full Text | Free Full Text

3. Royal College of obstetricians and gynaecologists reducing the risk of venous thromboembolism during pregnancy, April 2015. Reference Source

4. Knol HM, Schultinge L, Erwich JJ, et al.: Fondaparinux as an alternative anticoagulant therapy during pregnancy. J Thromb Haemost. 2010; 8(8): 1876-1879. PubMed Abstract | Publisher Full Text

5. Wiger EE, Reed JL: A retrospective analysis of fondaparinux versus enoxaparin treatment in women with infertility or pregnancy loss. Am J Reprod Immunol. 2009; 62(4): 253-260.

PubMed Abstract | Publisher Full Text

6. Gerhardt A, Zotz RB, Stockschlaeder M, et al.: Fondaparinux is an effective alternative anticoagulant in pregnant women with high risk of venous thromboembolism and intolerance to low-molecular-weight heparins and heparinoids. Thromb Haemost. 2007; 97(3): 496-497. PubMed Abstract | Publisher Full Text

7. Mazzolai L, Hohlfeld $P$, Spertini $F$, et al.: Fondaparinux is a safe alternative in case of heparin intolerance during pregnancy. Blood. 2006; 108(5): 1569-70. PubMed Abstract | Publisher Full Text

8. Nagler M, Haslauer M, Wuillemin WA: Fondaparinux - data on efficacy and safety in special situations. Thromb Res. 2012; 129(4): 407-417.

PubMed Abstract | Publisher Full Text 


\section{Open Peer Review}

\section{Current Peer Review Status: $\mathrm{X} X$}

\section{Version 1}

Reviewer Report 30 July 2020

https://doi.org/10.5256/f1000research.23336.r65571

(C) 2020 Othman M. This is an open access peer review report distributed under the terms of the Creative Commons Attribution License, which permits unrestricted use, distribution, and reproduction in any medium, provided the original work is properly cited.

\section{Maha Othman}

Biomedical and Molecular Sciences, Queen's University, Ontario, Canada

The authors report successful use of fondaparinux in managing heparin intolerance during pregnancy in a $37 \mathrm{y}$ old pregnant lady at her $11 \mathrm{w}$ of gestation.

Hypersensitivity reactions to heparin in pregnancy is not a new issue and is reported in 20\% of patients. The successful use of fondaparinux is not new either. So I am not sure if this is still worth reporting. Also, I am not sure I would agree with authors that the experience fondaparinux use in pregnancy is still limited.

The most interesting part of this case in my view is to identify the pathology underlying this poor obstetric history (repeatedly complicated pregnancies, labours and multiple IUFDs). The thrombophilia screen is all normal. The authors included APS work up, however these antibodies were only measured once; against the standard diagnostic guidelines. The possibility of APS still exists in this case and requires further investigation.

I encourage the authors to shift focus towards diagnosis of the pathology for this poor obstetric history; perform further investigations and rewrite the case report. This will provide some novelty and help educate the scientific community in similar cases.

Is the background of the case's history and progression described in sufficient detail? Partly

Are enough details provided of any physical examination and diagnostic tests, treatment given and outcomes?

Partly

Is sufficient discussion included of the importance of the findings and their relevance to future understanding of disease processes, diagnosis or treatment? 
Partly

Is the case presented with sufficient detail to be useful for other practitioners?

Partly

Competing Interests: No competing interests were disclosed.

Reviewer Expertise: Haemostasis, coagulopathies in placenta mediated complications, Women's Health

I confirm that I have read this submission and believe that I have an appropriate level of expertise to state that I do not consider it to be of an acceptable scientific standard, for reasons outlined above.

Reviewer Report 03 December 2019

https://doi.org/10.5256/f1000research.23336.r57377

(C) 2019 Middeldorp S et al. This is an open access peer review report distributed under the terms of the Creative Commons Attribution License, which permits unrestricted use, distribution, and reproduction in any medium, provided the original work is properly cited.

\section{Saskia Middeldorp}

Department of Vascular Medicine, Amsterdam Cardiovascular Sciences, Amsterdam UMC, University of Amsterdam, Amsterdam, The Netherlands

\section{Hanke Wiegers}

Amsterdam UMC, University of Amsterdam, Amsterdam, The Netherlands

This case report on fondaprinux in a pregnant woman with LMWH allergy does not lead to new insights into the knowledge of heparin allergy or fondaparinux.

Important references about the occurrence of type IV (?) allergy to LMWH and how to deal with this, have not been referenced (for instance, Schindewolf, Lancet) It is therefore surprising that the authors immediately chose to use fondaparinux and not other types of LMWH.

The authors imply causal inference between use of anticoagulants and the successful pregnancy outcome, which cannot be made on a single case.

Reference to guidelines regarding the use of LMWH to improve outcome in IUFD is missing.

Is the background of the case's history and progression described in sufficient detail? No

Are enough details provided of any physical examination and diagnostic tests, treatment given and outcomes? 
Yes

Is sufficient discussion included of the importance of the findings and their relevance to future understanding of disease processes, diagnosis or treatment?

No

Is the case presented with sufficient detail to be useful for other practitioners?

No

Competing Interests: No competing interests were disclosed.

Reviewer Expertise: VTE

We confirm that we have read this submission and believe that we have an appropriate level of expertise to state that we do not consider it to be of an acceptable scientific standard, for reasons outlined above.

The benefits of publishing with F1000Research:

- Your article is published within days, with no editorial bias

- You can publish traditional articles, null/negative results, case reports, data notes and more

- The peer review process is transparent and collaborative

- Your article is indexed in PubMed after passing peer review

- Dedicated customer support at every stage

For pre-submission enquiries, contact research@f1000.com 